\title{
O mosaico colorido da guará vermelha: a relação das cores com a condição feminina no romance de Maria Valéria Rezende
}

\author{
The colorful mosaic of the scarlet ibis: \\ the relationship of colors with the female condition in \\ Maria Valéria Rezende's novel
}

Ana Maria Soares Zukoski*

\begin{abstract}
RESUMO: O presente trabalho tem por objetivo apresentar uma análise interpretativa no que tange à presença das cores e as suas relações com a condição feminina no romance contemporâneo brasileiro $O$ voo da guará vermelha, publicado em 2005 pela autora Maria Valéria Rezende. As cores constituem-se como um elemento bastante presente e bastante significativo na construção do romance corpus desse artigo, acompanhando a trajetória dos protagonistas Irene e Rosálio. Tendo isso em vista, nós buscaremos analisar em que medida as cores sinalizam as transformações que ocorreram na vida da personagem feminina. Para isso, nós utilizaremos dos pressupostos teóricos da crítica feminista e dos estudos sobre simbologia, com pesquisadores/as tais como Brito (2014); Farina; Perez; Bastos (2006); Fernandes (2017); Sant'Anna; Junior; Garcia (2015); Chevalier; Gheerbrant (2018); Silva (2011), entre outros/as.
\end{abstract}

PALAVRAS-CHAVE: literatura de autoria feminina; simbologia das cores e condição feminina; O voo da guará vermelha; Maria Valéria Rezende.

ABSTRACT: This work aims to present an interpretative analysis regarding the presence of colors and their relation with the female condition in the contemporary Brazilian novel The flight of the scarlet ibis, published in 2005 by the author Maria Valéria Rezende. Colors are a very present and significant element in the construction of the novel corpus of this article, following the trajectory of the protagonists Irene and Rosálio. With that in mind, we seek to analyze in what measures the colors signal the transformations that occurred in the life of the female character. For this, we will use the theoretical assumptions of feminist criticism and studies on symbology, with researchers like Brito (2014); Farina; Perez; Bastos (2006); Fernandes (2017); Sant'Anna; Junior; Garcia (2015); Chevalier; Gheerbrant (2018); Silva (2011), among others.

KEYWORDS: Literature of female authorship; symbology of colors and feminine condition; The flight of the scarlet ibis; Maria Valéria Rezende.

\footnotetext{
* Doutoranda e Mestra em Letras - Estudos Literários pela Universidade Estadual de Maringá. E-mail: anazukoski@gmail.com. ORCID: http://orcid.org/oooo-0001-6231-701X.
} 


\section{Para início de conversa: a produção literária de mulheres interpelada pela condição feminina}

A falta de reconhecimento dos escritos de autoria feminina não significa que essa produção seja, de fato, menor ou inferior ${ }^{1}$. A sociedade ainda hoje apresenta inúmeros resquícios da cultura patriarcal que fornecem malhas de poder e controle no que tange às mulheres, mesmo que de forma velada. A deslegitimação da escrita de autoria feminina estaria ligada ao esforço de manter as mulheres enredadas na condição feminina, essencialmente patriarcal. Para Colasanti (1997, p.41), "aceitando a literatura feminina, a sociedade estaria aceitando aquele modelo de mulher que ela própria tanto nega, e que com tanto esforço estamos tentando impor”. A recusa dos escritos femininos diz mais respeito a questões sociais do que necessariamente ao texto escrito, que deveria ser o objeto de análise. Daí a importância de lançar luzes sobre os escritos femininos, buscando realizar trabalhos de cunho científico, a fim de romper com esse processo de marginalização e demonstrar que as autoras dispõem de qualidade estética e suas obras de literariedade, considerando que são esses os principais critérios de avaliação dos textos literários.

Assim, a escrita de autoria feminina, sobretudo no que tange aos textos literários, traz em seu âmago um aspecto que merece destaque, conforme pontua Colasanti (1997, p.41): "Literatura - reconhecível como tal - implica linguagem individual. E linguagem individual é transgressão, ruptura das normas, questionamento do já estabelecido”. Por linguagem individual, é compreensível a apropriação da linguagem pela escritora, que laborará com essa em seus escritos, buscando não apenas o domínio das palavras, mas também o domínio de si mesma. Esse reconhecimento da possibilidade de possuir uma linguagem

\footnotetext{
1 Essa marginalização da literatura de autoria feminina evidencia-se quando analisamos as premiações literárias. Em levantamento realizado por meio dos sites dos prêmios Jabuti, Machado de Assis e Camões, constatamos que o Prêmio Jabuti entre os anos de 1959 a 2018 distribuiu 114 prêmios sendo concedidos 95 a autores do sexo masculino e apenas 19 para autoras. O cenário pouco se modifica no que tange ao Prêmio Machado de Assis, que no recorte temporal de 1941 a 2017, dos 72 prêmios atribuídos, 63 foram para homens e 9 para mulheres escritoras. $O$ Prêmio Camões entre os anos de 1988 a 2018 outorgou o total de 30 prêmios, sendo 24 autores masculinos e apenas 6 autoras agraciadas. A discrepância revelada por esses dados demonstra como a produção literária feminina continua à margem no campo literário.
} 
individual implicaria "não apenas à legitimação de transgressão por parte das mulheres, como à afirmação inequívoca de que transgredir faz parte da sua natureza" (COLASANTI, 1997, p. 41). O processo de escrita auxilia na subversão dos falidos valores patriarcais que giram em torno do controle e da submissão feminina, sendo, portanto, uma valiosa aliada na superação, mesmo que parcial, da condição feminina.

A conquista do campo intelectual, melhor dizendo, a inclusão das mulheres nas universidades e instituições de ensino formal, propiciou uma grande transformação, sobretudo no que tange à questão da escrita, que foi, e ainda é, uma grande aliada das mulheres, pois, por meio dela, dão vazão às suas vozes, suas representações e suas angústias. Cumprem, assim, o caráter crítico da literatura, ao denunciarem a marginalidade, a condição feminina de opressão, o machismo de cada dia e tantas outras questões que precisam enfrentar. A escrita literária de mulheres pode ser compreendida como um instrumento de luta, resistência e busca pelo autoconhecimento. É a arte, mais do que nunca, assumindo sua função social.

Maria Valéria Rezende estreou tardiamente na literatura, mas já acumula prêmios por suas obras publicadas. Com O voo da guará vermelha (2005), no ano de 2007, a autora santista figurou como finalista no Prêmio Zaffari \& Bourbon. Já Quarenta dias (2014) lhe rendeu o primeiro lugar na categoria romance do Prêmio Jabuti em 2015, finalista no Prêmio Estado do Rio de Janeiro também em 2015 e semifinalista no Prêmio Oceanos, no referido ano. Outros Cantos (2016) por sua vez alcançou o Prêmio São Paulo de Literatura na categoria romance, o terceiro lugar na mesma categoria no Prêmio Jabuti e na categoria de Literatura Brasileira o Prêmio Casa de las Américas, todos em 2017. A autora, que também escreve literatura infanto-juvenil, foi agraciada com o Prêmio Jabuti em 2009 pela obra No risco do caracol (2008) e foi premiada pelo mesmo prêmio em 2012 com a obra Ouro dentro da cabeça (2012). Figurou como finalista em diversas premiações como Prêmio Jabuti, Prêmio Cidade de Belo Horizonte, Prêmio Portugal Telecom, Prêmio Oceanos entre outros. A escritora vem despontando como um expoente na seara da literatura brasileira contemporânea, com publicações recentes, como é o caso do romance Carta à rainha louca (2019). 
O romance corpus desse artigo, O voo da guará vermelha, foi publicado em 2005 e apresenta diversas temáticas caras à literatura de autoria feminina contemporânea. Em suma, o enredo delineia a história do encontro inusitado entre o pedreiro analfabeto Rosálio e a prostituta soropositiva Irene, que permite a ambos um crescimento humano profundo e um encontro de histórias, contadas por ele e ouvidas por ela. Mesmo com pouco tempo de vida que lhe resta e com o exaurimento das forças, Irene se permite viver uma história intensa de afeto e consegue ensinar as precárias letras que sabe ao companheiro, o que propicia que ele realize o sonho de ser um contador de histórias, redimensionando, assim, sua trajetória existencial.

O voo da guará vermelha, romance marcado pela delicadeza da escrita e pelo tom altamente lírico, aborda, entre outras questões, a marginalização social imputada à protagonista Irene devido à sua condição de prostituta, assim como o estigma de sua profissão e o julgamento social que acabam por restringir as suas identidades e como isso afeta a representação que a personagem dispõe de si mesma. Discorre ainda sobre as relações entre as contações de histórias e a escrita que são firmadas entre os protagonistas, Irene e Rosálio, evidenciando o modo como essa permuta de experiências colabora no processo de (re)construção da subjetividade de Irene e de uma nova imagem para si, não mais associada à prostituição. Apesar de não ser o foco do presente artigo, vale ressaltar que a protagonista percorre um processo de (re)construção identitária. Alain Touraine, na obra $O$ mundo das mulheres (2010), cunhou a expressão "construir a si mesma”, que se relaciona diretamente ao processo de subjetivação feminina que implica "afirmar-se como mulheres e não somente em libertar-se de uma feminilidade imposta pelos homens, ainda que elas rejeitem, toda forma de dependência e a condenem quando a percebem ao redor ou dentro delas" (TOURAINE, 2010, p. 44). É preciso que ocorra um amadurecimento na visão feminina que constrói sua representação, para esta se libertar das amarras do poder masculino e se redirecionar à afirmação como mulher-sujeito. Para Zolin (2009, p. 2019, grifo da autora), “a mulher-sujeito é marcada pela insubordinação aos referidos paradigmas, por seu poder de decisão”. Os paradigmas referidos pela pesquisadora são os patriarcais, que atuam para restringir as mulheres à condição de objetos. Irene percorre esse trajeto, 
redirecionando sua visão sobre si mesma e enveredando pelo caminho do amor próprio e do reconhecimento enquanto sujeito de sua própria história. Em alguns romances contemporâneos, como em O voo da guará vermelha(2005), de Maria Valéria Rezende, a escrita desempenha uma importante função, pois é ela que legitima o processo de subjetivação. A obra é permeada por um mosaico colorido, visto que as cores, recorrentemente presentes na narrativa e nos títulos dos capítulos, sugerem e acompanham as transformações vivenciadas pelos personagens.

No que tange à fortuna crítica do romance a partir do recorte temático proposto no presente artigo, isto é, a simbologia das cores, dois trabalhos destacam-se, sendo eles: Sobre Rosálio e Irene: uma semiótica dos sentidos das cores em $\mathrm{O}$ voo da guará vermelha, de Maria Valéria Rezende, publicado em 2014 por Clivânia Ramos de Brito, que apresenta uma análise de caráter semiótico focalizando as mudanças psicológicas das personagens por meio das cores; e As cores e a profundidade da vida em $\mathrm{O}$ voo da guará vermelha de Maria Valéria Rezende, publicado em 2017 por Maria Aparecida Barreto Fernandes, que enfatiza em seu trabalho as cores do romance com a formação das identidades individuais e coletivas presentes na narrativa. Considerando os trabalhos realizados até o momento e que constituem parte da fortuna crítica do romance, procuraremos discorrer sobre as relações das cores com a protagonista Irene, buscando demonstrar como as cores acompanham as transformações da personagem mulher que rompe, mesmo que no nível individual, com as condições femininas de marginalização. Dessa forma, lançamos luz ao romance a partir de outra perspectiva, considerando que a nossa hipótese de trabalho relaciona as cores com o rompimento das condições femininas, tencionando enriquecer os estudos críticos sobre a prosa rezendiana.

A respeito da metodologia adotada, utilizar-nos-emos do método qualiinterpretativo e bibliográfico, realizando na próxima seção a análise interpretativa do romance corpus a partir da fundamentação teórica erigida, a fim de lançar luz à relação entre cores e a ascensão existencial da personagem Irene. 


\section{A simbologia "do cinza ao azul sem fim": a ruptura existencial com a condição feminina}

Presente desde o título, as cores acompanham a construção dos capítulos e ajudam a compor a ambientação, assim como assinalam as transformações pelas quais a protagonista trilhou. Cor é utilizada para "referir-se à sensação consciente de uma pessoa, cuja retina se acha estimulada por energia radiante" (FARINA; PEREZ; BASTOS, 2006, p. 1). A partir da conceituação dos autores acima, a percepção da cor estabelece com a pessoa uma relação sinestésica, isto é, provoca sensações ou percepções naqueles que estão em contato visual com essas ondas luminosas.

A respeito dessas emoções provocadas pelo contato com as cores, os pesquisadores Farina, Perez e Bastos (2006, p. 2) explicam que elas podem produzir “impressões, sensações e reflexos sensoriais [...] porque cada uma delas tem uma vibração determinada em nossos sentidos e pode atuar como estimulante ou perturbador na emoção, na consciência e em nossos impulsos e desejos”. Devido à possibilidade de ocasionar reações, as cores são utilizadas pelos mais diversos campos, objetivando influenciar as pessoas, como é o caso do uso das cores na propaganda e publicidade ou nos ambientes em que há um incentivo ao consumo ou ainda reforçar uma ideia por meio da simbologia que a cor especificamente escolhida dispõe.

Sant'Anna, Rocha Junior e Garcia, na obra Propaganda: teoria, técnica e prática (2015, p. 74), afirmam que as cores, assim como os sons, têm "o papel de moldura para a mensagem ali contida”. A ideia apresentada pelos pesquisadores, quando ampliada, é passível de ser aplicada à análise do romance corpus desse artigo. Todos os capítulos dessa obra de Maria Valéria Rezende (2014) são nomeados com cores, compondo um mosaico colorido. As cores aí servem não apenas como uma "moldura" para cada capítulo, mas estão relacionadas com as personagens e suas trajetórias, cumprindo a função de evidenciar e reforçar determinados caracteres do romance. De acordo com Fernandes (2017, p. 8), no romance de $O$ voo da guará vermelha "a representação das cores assume sentidos expressivos sobre a condição existencial das personagens, seus dramas, suas perdas, embates, situações de desigualdades sociais e, principalmente, as 
formas de resistência”. Brito (2014, p. 14) destaca que Rezende recorre "às cores para dar sentido à relação das personagens entre si e com o fato narrado”. Assim, as cores colaboram de forma significativa para a construção dos sentidos em $O$ voo da guará vermelha, engenhando o processo de subjetivação de Irene, o relacionamento entre ela e Rosálio, assim como o ambiente socialmente opressor.

O romance é composto por 17 capítulos, intitulados respectivamente: cinzento e encarnado, verde e negro, roxo e branco, ocre e rosa, amarelo e bonina, verde e ouro, vermelho e prata, ouro e azul, encarnado e amarelo, verde e ocre, alaranjado e verde, azul e amarelo, ocre e ouro, azul e encarnado, cinzento e todas as cores, vermelho e branco, e azul sem fim. Há uma oscilação entre cores com uma conotação positiva, em geral as cores quentes, e cores com uma conotação negativa, comumente as cores frias. Podemos relacionar essa oscilação com a trajetória da personagem principal, Irene, que também teve ápices e declínios ao longo do processo de subjetivação.

A obra conta com um narrador heterodiegético que, por sua vez, em alguns momentos utiliza o recurso do discurso indireto livre, trazendo em sua voz a fala dos personagens. A construção da narrativa é aliada ao uso das cores, presentes no ambiente, nas roupas e nos objetos das personagens principais. Destacamos, devido à recorrência e à importância, o uso de sete cores imprescindíveis: cinzento/preto, verde, amarelo, encarnado/vermelho e azul. Vale ressaltar que as cores que se apresentam juntas, isto é, cinzento/preto e encarnado/vermelho foram agrupadas na presente análise, exclusivamente, por um critério didático. Dito de outra forma, por difundirem simbologias consoantes, optamos por analisá-las juntas. Considerando que o romance conta com uma narrativa caracteristicamente contemporânea, a lineariedade não é seguida de acordo com a trajetória da protagonista, daí as diferentes recorrências de cores ao longo dos capítulos. Entretanto, para fins didáticos, analisaremos as cores pautando-nos na evolução do percurso dos protagonistas, com enfoque na personagem Irene.

A respeito da cor cinza, sua simbologia está relacionada com a problemática da opressão. De acordo com Farina, Perez e Bastos (2006, p. 98), a cor cinza "simboliza a posição intermediária entre a luz e a sombra". Noutras palavras, uma espécie de entre-lugar, não pertencente integralmente a nenhuma das esferas. Apresenta ainda associações afetivas como "tédio, tristeza, 
decadência, [...] desânimo, [...] carência vital” (FARINA; PEREZ; BASTOS, 2006, p. 98). O cinzento presente na obra corrobora a construção de uma ambientação fria e opressora, consoante à marginalização que a personagem vivencia. Pode representar também a ausência de cores, isto é, a falta de sentimentos e emoções prementes: "Hoje foram-se todos, só ficaram a não cor e o silêncio de cinza neste mundo" (REZENDE, 2014, p. 10). O narrador faz associações entre as emoções e a cor cinza, espécie de metáfora que reflete o estado de ânimo inicial. Nota-se que a ambientação pautada nessa cor reforça os sentimentos negativos, representando uma atmosfera opressiva, como é a vida de Irene antes de conhecer o pedreiro Rosálio.

Assim como a cor cinza, a cor preta $^{2}$ também se relaciona com o estado inicial das personagens, sendo definida por Farina, Perez e Bastos (2006) como "a cor da vida interior sombria e depressiva. [...] Associação afetiva: [...] miséria, pessimismo, [...] tristeza, frigidez, desgraça, dor, temor, negação, melancolia, opressão, angústia” (p. 98). Ao considerar essa simbologia face ao romance, não há como ignorar que a opressão e a miséria estão relacionadas com a condição social que permeia, sobretudo, a trajetória da personagem Irene, pobre e prostituta, estigmatizada e marginalizada. A condição de uma vida interior "sombria e depressiva" está concatenada com a representação negativa que Irene faz de si mesma, sendo que a cor negra marca a presença avassaladora do estigma de prostituta.

Conforme o relacionamento entre o pedreiro e a prostituta soropositiva caminha, as cores começam a se fazer mais presentes na vida dos dois personagens: "fizesse o amarelo, o azul, o verde, o rosado expulsar o cinza desta alma que eu carrego como uma barra de chumbo" (REZENDE, 2014, p. 83). O excerto explicita a influência das cores e o desejo da personagem em que estas consigam expulsar o cinza, retomando novamente a ideia da transformação. Essa oposição entre o cinza e as demais cores também reforça a ideia da separação destas de acordo com o modo de vida que levavam. Cinzento em referência a

\footnotetext{
${ }^{2} \mathrm{O}$ presente artigo não entrará no mérito das discussões sobre as questões de raça/cor, assim como não tenciona, absolutamente, soar como preconceituoso ou racista. Utilizamos as simbologias da cor preto/negro contidas em dicionários de símbolos, objetivando relacioná-las com a análise da obra $O$ voo da guará vermelha.
} 
quando sobreviviam, e todas as cores para reportar ao relacionamento que serviu como mote para suas vidas saírem da sobrevivência e passarem à agência, à vida propriamente dita: "então vai descobrindo que o cinzento cede espaço aqui, ali, acolá, para manchas de outras cores que antes não enxergava porque a cidade não era lugar de vida” (REZENDE, 2014, p. 137). Descortinamos, assim, a importância do processo de construção das personagens por meio das cores, que assinalam as transformações positivas. Ao referir-se à cidade como "um lugar que não era de vida”, remete-se, ainda que indiretamente, à conotação negativa que a cor cinza dispunha na trajetória de Irene, contraposta à presença das cores, ligadas à presença de Rosálio, peça fundamental no descortinar da visão que Irene faz de si mesma.

O verde, por sua vez, está relacionado com o início das transformações. Para os pesquisadores Chevalier e Gheerbrant, "o verde é o despertar da vida" (2018, p. 939). A utilização dessa cor no romance pode ser relacionada com a decisão de Irene em começar a escrever, e o fazendo pela primeira vez "vestida de verde [...] Irene, revestida de esperança” (REZENDE, 2014, p. 19). A escrita é bastante significativa no romance, considerando que é por meio dela que a personagem prostituída iniciará a sua resistência contra as amarras da condição feminina. $\mathrm{O}$ fato de uma personagem tão marginalizada como Irene escrever e, mais do que isso, ensinar outra pessoa a escrever, no caso, Rosálio, demonstra uma ruptura com os padrões patriarcais, ainda estabelecidos na sociedade contemporânea. A escrita possibilitou à protagonista galgar um importante e inevitável processo de subjetivação, pois, por meio do ato de escrever, Irene promove o florescimento de sua subjetividade e das identidades que melhor a representam. Assim, é compreensível que Irene tenha despertado para a vida renovada pela esperança, que também é algo associado a essa mesma cor, compreendendo situações e relações que antes lhe eram desconhecidas.

Outra simbologia atribuída ao verde remonta a "um conhecimento profundo, oculto, das coisas e do destino" (CHEVALIER; GHEERBRANT, 2018, p. 941). Associar o verde a essa significação remonta compreender que o conhecimento adquirido com o relacionamento deles não diz respeito a algo corriqueiro ou habitual. Esse conhecimento não reporta aquele sistemático apreendido por meio de regras ou livros normais, mas sim por meio da 
experiência vivida, o que implica construção. Rosálio e Irene foram transformados por meio dessa experiência, utilizando o conhecimento adquirido para se reinventarem e descobrirem o melhor de si. Pode ser relacionado com a troca de experiências entre o pedreiro e a prostituta, visto que possibilita a eles um grande crescimento.

A contação de histórias de Rosálio e as letras que Irene lhe ensina ultrapassam a barreira material, agregando sentimentos e emoções àssuas identidades, que estão em constante transformação. A grande presença da cor verde nos títulos dos capítulos possibilita depreender que esses significados, a esperança, o conhecimento e/ou despertar da vida percorrem a narrativa em sua totalidade, podendo ser entendidos como a semente que floresceu uma nova perspectiva para a vida.

Ao seguir o percurso de amadurecimento das relações dos personagens, o amarelo está presente com recorrência, em diferentes tonalidades, como ocre e ouro. Também sendo associado à ideia de conhecimento, como o verde, o ouro cumpre uma figuração análoga. A repetição do ouro no título de diversos capítulos reforça que ao longo de sua trajetória Irene vai progressivamente acumulando novas experiências e sabedoria, conseguindo livrar-se das vendas que a ótica social lhe impunha e romper com as algemas da condição feminina. Assim, essa cor dispõe relações com o processo de subjetivação feminina da protagonista que resultou na liberdade do sentimento de culpa, assim como o reconhecimento de que era digna de viver um grande amor, além de representar a simbologia do tesouro, pertinente ao momento vivenciado pela protagonista.

Os autores Chevalier e Gheerbrant (2018) atribuem ao ocre inúmeras simbologias referentes a ideias de prudência, sabedoria e constância na tristeza e nos infortúnios. Ao relacioná-las com o romance, simboliza o esforço de Irene, mesmo diante das adversidades, em continuar escrevendo e construindo sua nova autorrepresentação. Ressalta-se que a escrita de Irene é totalmente motivada pela sua própria vontade, não tendo influências de seu companheiro. Caracterizada como uma escrita catártica é por meio da mistura das palavras do âmbito da fantasia com a realidade que a personagem consegue organizar sua interioridade, desprendendo-se da antiga representação, pejorativa e autodepreciativa, ligada à prostituição. A persistência da presença do ocre remete 
justamente a essa sapiência da protagonista em conseguir aproveitar-se das situações adversas para crescer, driblando as barreiras e obstáculos que não faltaram ao longo de sua trajetória. Assim, essa cor faz referência ao conhecimento que Irene dispunha antes de conhecer Rosálio, aquele que lhe permitiu lidar com a sua profissão: a prostituição. Tal conhecimento não a abandonou e foi agregado àquele construído junto com o pedreiro, isto é, o processo de subjetivação. Os conhecimentos intrinsecamente ligados possibilitam que Irene seja completa em sua incompletude. O ocre também se aproxima do marrom e da argila, sugerindo que esse marrom transforma-se em ouro, isto é, metaforiza a base da aquisição de um tesouro.

O amarelo também remete a "conforto, [...] orgulho, esperança" (FARINA; PEREZ; BASTOS, 2006, p. 97). Em relação à trajetória de Irene, depreendemos que está relacionado ao estado de ânimo que o relacionamento com Rosálio proporcionou a ela: "quer ir comprar um ovo, de gema bem amarela [...] Rosálio comeu, fartou-se, insiste com a mulher para que coma também, acha graça no bigode amarelo que ela tem agora na cara magra” (REZENDE, 2014, p. 41-42). Além da cor amarela, apresentamos também a questão do ovo, tido por Chevalier e Gheerbrant (2018, p. 675) como "símbolo de prosperidade”. O amarelo está associado a uma representação positiva, colaborando para a construção dos sentidos no romance. As cores permeiam as alterações, sinalizando as etapas percorridas pela personagem.

O vermelho, mencionado desde o título da obra, é apresentado em inúmeras variações, abrangendo também o encarnado e a bonina. A referência ao encarnado é significativa e remete ao vermelho da carne. Não diz respeito a qualquer vermelho, uma vez que a relação com a carne suscita a seguinte simbologia: "A carne assume também um valor de intimidade, não apenas corporal, mas espiritual [...] designa o princípio mais profundo da pessoa humana, a sede do coração" (CHEVALIER; GHEERBRANT, 2018, p. 188-189). A partir dessa simbologia, verificamos que a "fome de encarnados" (REZENDE, 2014, p. 10) sentida pelos personagens remete ao desejo e também à urgência de superar essa marginalização na qual se encontram inseridos, ou seja, tingir com as cores da vida as suas existências, e isso só é realizável a partir da construção com Irene. 
Já no que tange à cor bonina, esta é uma espécie de vermelho escuro. Para os autores Farina, Perez e Bastos (2006, p. 99), o vermelho "é signo de força, de energia, de redenção”. A dedicação com a qual Irene entrega-se à escrita, e, consequentemente, à sua reconstrução, considerando a relação existente entre o ato de escrever e o processo de subjetivação feminina, sendo o primeiro um mecanismo de desenvolvimento do segundo, está relacionada com a simbologia do vermelho, demonstrando a força de vontade da protagonista em se reconstruir e cumprir uma espécie de redenção: "escolhe o cor de bonina, quase novo, pouco usado, guardado como promessa de alguma coisa melhor que o dia a dia cinzento em que vive há tanto tempo" (REZENDE, 2014, p.42). Com efeito, a protagonista estabelece essa relação positiva com a cor vermelho, assim como, no primeiro capítulo, estabelece uma relação contrária ao cinzento.

O encarnado, nessa tonalidade avermelhada, nas palavras dos autores Farina, Perez e Bastos (2006, p. 99), "simboliza uma cor de aproximação, de encontro". Ambas as simbologias são próximas do novo status da vida que Rosálio e Irene passam a levar juntos. A ideia de liberdade, no que diz respeito às convenções sociais, e também à liberdade de amar, ou seja, de entregar-se à paixão. A aproximação dos dois permitiu que eles alçassem a essa nova representação, além de se verem livres das amarras psíquicas que os resignavam a uma vida de miséria, física e psicológica. Vale ressaltar que os níveis de opressão sofridos pelos personagens, sobretudo por Irene, estendem-se para além dos níveis psicológicos, todavia, a imobilidade estrutural da sociedade impede que os mesmos superem essas barreiras físicas, ocorrendo, portanto, uma ruptura individual no que tange aos ideários sociais. O vermelho marca de forma mais contundente as alterações alcançadas pelos dois personagens. Assim, ambos passam do cinzento e da ideia de uma existência morta e esvaziada para uma vida mais premente, marcada pela força e energia do vermelho.

Por fim, Chevalier e Gheerbrant (2018, p. 107) ponderam sobre o azul, considerando que essa cor "sugere uma ideia de eternidade tranquila e altaneira". A ideia de eternidade é associada às transformações, demonstrando a profundidade delas, isto é, não passíveis de dissuasão. Portanto, a nova representação de Irene não é mais abalada facilmente pelas estruturas de poder social. Assim, o azul passa a ser associado com a sensação de paz, em consonância 
com Farina, Perez e Bastos (2006). É significativo que o último capítulo seja nomeado com essa cor: "Azul sem fim”. Podemos relacioná-lo com o infinito: "O céu é azul e por isso o azul é a cor do divino, a cor do eterno. [...] É a cor do céu sem nuvens. Dá a sensação do movimento para o infinito” (FARINA; PEREZ; BASTOS, 2006, p. 102). Desse modo, o azul infinito com a morte de Irene simboliza a liberdade da prostituta, que só poderia realmente ser alcançada em sua plenitude por meio da morte, uma vez que, mesmo tendo se transformado e feito as pazes consigo mesma, o contexto social continua inalterado, não dispondo de elementos práticos para superar a opressão que não poupa a sua vida, isto é, só na morte Irene conseguiu se libertar dos paradigmas sociais: "eu sei que por onde eu for a minha guará vermelha, minha mulher encantada, vai sempre me acompanhar, voando entre o azul e mim, e ela quer ouvir meus contos” (REZENDE, 2014, p. 157). O azul direciona e reforça que a metáfora da guará vermelha, contida já no título da obra, se refere à figura de Irene. A escrita lhe possibilita que voe em sua trajetória, ao longo do processo para a sua transformação em sujeito de sua história e a morte permite que ela revoe pelo céu de um azul sem fim.

A reflexão de Silva (2011, p. 236) caminha nessa direção: “a caracterização feminina da ave [...] numa metáfora apropriada para o enredo da narrativa, compacta em Irene [...] atributos da ave (pelo voo com possibilidade de liberdade e pela coloração como dinâmica de vida)”. A escolha da cor vermelha para representar essa guará, grafada como sendo um substantivo feminino, ainda que as normas gramaticais postulem como de um substantivo masculino, reforçam a ideia de que Irene corresponda a essa representação.

O desfecho tanto da ave quanto o de Irene também possui pontos de intersecção: “Rosálio sente dó, tanto dó desta mulher!, faz lembrar aquela guará, vermelha [...] que ele uma vez encontrou enredada nos galhos de um espinheiro, as penas ainda mais rubras [...] [a] sangrar até morrer, sozinha, desamparada" (REZENDE, 2014, p. 16). O vermelho aqui também representa o sangue, derramado ao final de ambas as vidas, tanto da ave da lembrança de Rosálio como a vida de Irene. O contexto da morte também é significativo, marcado pelo desamparo e solidão. O "espinheiro" pode ser lido como a metáfora para essa sociedade que "crava seus espinhos morais" nas mulheres que se encontram em 
situação análoga a de Irene: "Rosálio colhe nos braços a sua guará vermelha, colhe na boca o sorriso que verte um encarnado vivo e cobre inteira de plumas, tingindo todas as mágoas, transfigurando-lhe a dor" (REZENDE, 2014, p. 156). O excerto flagra outra comparação de Irene com a ave, com a forte presença do vermelho, por meio do sangue que cobre o corpo inteiro da prostituta, assim como a guará é recoberta por plumas vermelhas. Essa cor, segundo Farina, Perez e Bastos (2006, p. 99), também "pode remeter à proibição e à revolução [...] tomado positivamente é o que dá vida, que purifica”. Tais remissões são coerentes com a postura da protagonista, que consegue romper com as proibições inculcadas pela moral social, estabelecendo uma verdadeira revolução dentro de seu ser, confirmando que nem a prostituição nem a sociedade podem lhe usurpar a subjetividade, que cultivada pela escrita floresceu e possibilitou o crescimento de uma nova Irene, livre psicologicamente das amarras sociais. Isso aparece refletido na forma como a protagonista começa a encarar a vida, flagrado no excerto a seguir: "hoje foi ver o filho, achou-o mais engraçado, capaz de brincar com ela [...] Irene foi achando que ele estava mais corado, mais vivo, ou é ela que está mais viva e vê tudo diferente?” (REZENDE, 2014, p. 100). O processo de subjetivação, reforçado pela simbologia da cor vermelha, aliado à aceitação, viabiliza que a protagonista consiga enxergar a vida de modo diferente, mais vivo, isto é, mais colorido, com cores mais vibrantes. As mudanças proporcionadas pela descoberta da capacidade de escrever e, portanto, criar, influenciam na sua representação e consequentemente no modo como ela passa a enxergar a vida.

A guará vermelha, entendida aqui como a protagonista, ao longo de sua trajetória ruma pelos céus em busca da liberdade no que tange às condições sociais, entretanto, seu voo só atinge a completude com a morte, pois a sociedade contemporânea, com os resquícios patriarcais, dificulta que pessoas marginalizadas construam mudanças efetivas no sistema.

\section{Considerações possíveis}

Com o desenvolvimento das análises no presente artigo, buscamos demonstrar que a trajetória da protagonista de $O$ voo da guará vermelha, de 
Maria Valéria Rezende, rompendo com as amarras da condição feminina, relaciona-se com as cores que permeiam a constituição do romance.

Ao realizar a busca pela subjetivação abordada por Touraine (2010), Irene, revestida de verde esperança, encontra na escrita amarela o conhecimento necessário para colocar no papel todos os sentimentos e as aflições que a acometem e alcançar o direito à voz e à expressão, lutando pelo seu lugar no mundo. Rezende, quando questionada, em uma entrevista concedida à Revista Claudia, em setembro de 2017, pela sua predileção a protagonistas do sexo feminino, responde que "as mulheres estão sustentando o Brasil, segurando todas as barras e sofrendo demais. Elas precisam de uma dose de coragem e outra de loucura para dar conta de tudo" (REZENDE, 2017, p. 108). Essa fala reflete a representação ficcional de Irene, que encontra a força e a dedicação necessárias, vibrantes como o vermelho para empreender a sua busca por si mesma.

A trajetória de Irene nos convida a pensar nas desigualdades sociais, na exploração, na objetificação de mulheres e na falta de opções que lhes permeiam a existência, pois, ao invés de lhe atribuir julgamentos vilipendiosos, o romance discute, entre outras questões, o lado menos visível da questão da prostituição. $\mathrm{O}$ desfecho lamentável da personagem principal reflete uma peremptória crítica social no que tange à situação das mulheres prostituídas, pois, se afastando de clássicos como A dama das camélias (1848) e Lucíola (1862), de Alexandre Dumas e José de Alencar, respectivamente, a morte de Irene não traz à baila um possível cunho moralista para o romance; contrariamente, chama atenção para a exploração dessas mulheres, que na realidade são vítimas da própria sociedade regulada por práticas e pensamentos herdados do patriarcado, tornando-as duplamente vítimas dos pressupostos da condição feminina.

Ademais, percebemos que as cores permeiam essa trajetória da prostituta, pois, conforme buscamos demonstrar no desenvolvimento das análises desse artigo, a presença das cores assinala os momentos pelos quais os personagens percorrem, sendo o cinza o símbolo da marginalização inicial, o verde o início da esperança em alterar suas vidas, o amarelo o conhecimento adquirido para alçar mudanças no nível emocional/psicológico, o vermelho marcando a força do processo e o azul, sinalizando a permanência das alterações e também a crítica à sociedade que não permite mudanças efetivas no sistema social. 


\section{Referências}

ALENCAR, José de Alencar. Lucíola. Rio de Janeiro: Nova Fronteira, 2016.

BRITO, Clivânia Ramos de. Sobre Rosálio e Irene: uma semiótica do sentido das cores em $O$ voo da guará vermelha, de Valéria Rezende. 2014. $31 \mathrm{f}$. TCC (Graduação em Letras) - Centro de Integração Acadêmica, Universidade Estadual da Paraíba, Campina Grande, 2014. Disponível em: http://dspace.bc.uepb.edu.br/jspui/handle/123456789/4408. Acesso em: 27 jun. 2020.

CHEVALIER, Jean; GHEERBRANT, Alain. Dicionário de símbolos: mitos, sonhos, costumes, gestos, formas, figuras, cores, números. 31. ed. Rio de Janeiro: José Olympio, 2018.

COLASANTI, Marina. Por que nos perguntam se existimos. In: SHARPE, Peggy (Org.) Entre resistir e identificar-se: para uma teoria da prática da narrativa brasileira de autoria feminina. Florianópolis; Goiânia: Editora Mulheres; Editora da UFG, 1997. p. 33-42.

DUMAS FILHO, Alexandre. A dama das camélias. São Paulo: Nova Alexandria, 2012.

FARINA, Modesto; PEREZ, Clotilde; BASTOS, Dorinho. Psicodinâmica das cores em comunicação. 5. ed. São Paulo: Editora Edgard Blücher, 2006.

FERNANDES, Maria Aparecida Barreto. As cores e a profundidade da vida em O voo da guará vermelha de Maria Valéria Rezende. 2017. 31 f. TCC (Graduação em Letras) - Departamento de Letras e Humanidades, Universidade Estadual da Paraíba, Catolé do Rocha, 2017. Disponível em:

http://dspace.bc.uepb.edu.br/jspui/handle/123456789/14209. Acesso em: 27 jun. 2020.

PREMIADOS por edição. In: PRÊMIO Jabuti. São Paulo: Prêmio Jabuti, 2019. Disponível em: https://www.premiojabuti.com.br/premiados-poredicao/. Acesso em: 12 fev. 2019.

PRÊMIO Camões de Literatura. In: BIBLIOTECA Nacional. Rio de Janeiro: Biblioteca Nacional, 2019. Disponível em:

https://www.bn.gov.br/explore/premios-literarios/premio-camoes-literatura. Acesso em: 12 fev. 2019.

PRÊMIOS Literários da ABL. In: ACADEMIA Brasileira de Letras. Rio de Janeiro: Academia Brasileira de Letras, 2019. Disponível em:

http://www.academia.org.br/academia/premios. Acesso em: 12 fev. 2019.

REZENDE, Maria Valéria. Carta à rainha louca. Rio de Janeiro: Alfaguara, 2019 . 
REZENDE, Maria Valéria. Entrevista a Patrícia Zaidan. Revista Claudia. São Paulo: Abril, set. 2017.

REZENDE, Maria Valéria. No risco do caracol. Belo Horizonte: Autentica Editora, 2011.

REZENDE, Maria Valéria. O voo da guará vermelha. Rio de Janeiro: Objetiva, 2014.

REZENDE, Maria Valéria. Ouro dentro da cabeça. Belo Horizonte: Autentica Editora, 2012.

REZENDE, Maria Valéria. Outros Cantos. Rio de Janeiro: Alfaguara, 2016.

REZENDE, Maria Valéria. Quarenta dias. Rio de Janeiro: Objetiva, 2016.

SANT'ANNA, Armando; ROCHA JUNIOR, Ismael; GARCIA, Luiz Fernando Dabul. Propaganda: teoria, técnica e prática. 9. ed. São Paulo: Cengage Learning, 2015.

SILVA, Antonio de Pádua Dias da. A diferença na autoria feminina contemporânea. In: ZOLIN, Lúcia Osana; GOMES, Carlos Magno (Org.). Deslocamentos da escritora brasileira. Maringá: Eduem, 2011. p. 231-245.

TOURAINE, Alain. O mundo das mulheres. Tradução de Francisco Morás. 2. ed. Petrópolis: Editora Vozes, 2010.

ZOLIN, Lúcia Osana. Crítica feminista. In: BONNICI, Thomas; ZOLIN, Lúcia Osana (Org.). Teoria Literária: abordagens históricas e tendências contemporâneas. 3. ed. Maringá: Eduem, 2009. p. 217-242.

Artigo recebido em 18 de março de 2020 e aceito em 18 de julho de 2020. 